\title{
Undetermined colitis
}

INSERM

\section{Source}

INSERM. (1999). Orphanet: an online rare disease and orphan drug data base.

Undetermined colitis. ORPHA:103920

Underterminate colitis designates a rare inflammatory bowel disease that clinically resembles Crohns disease and ulcerative colitis (see these terms) but that cannot be diagnosed as one of them after examination of an intestinal resection specimen. 